\title{
Maturação fisiológica de sementes de quaresmeira
}

\author{
José Carlos Lopes ${ }^{(1)}$, Paulo César Dias(2) e Márcio Dias Pereira(3)
}

\begin{abstract}
(1)Universidade Federal do Espírito Santo, Centro de Ciências Agrárias, Dep. de Fitotecnia, Caixa Postal 16, CEP $29500-000$ Alegre, ES. E-mail: sementes@cca.ufes.br (2)Universidade Federal de Viçosa, Centro de Ciências Biológicas e da Saúde, Dep. de Biologia Vegetal, CEP 36570-000 Viçosa, MG. E-mail: diaspc@bol.com.br (3)Escola Família Agrícola São João de Garrafão, Vila São João de Garrafão, CEP 29645-000 Santa Maria de Jetibá, ES. E-mail: marciobj@hotmail.com
\end{abstract}

\begin{abstract}
Resumo - O presente trabalho objetivou estudar a maturação fisiológica de sementes de quaresmeira (Tibouchina granulosa Cogn.). Cada inflorescência foi identificada em sua respectiva data de antese. Os frutos foram colhidos semanalmente para avaliações de diâmetro, peso, coloração, grau de umidade e massa de matéria seca. As sementes foram avaliadas quanto à massa de 1.000 sementes, velocidade e porcentagem de germinação. As determinações foram conduzidas com quatro subamostras de 50 frutos e sementes, por colheita, em delineamento inteiramente casualizado. A maturação fisiológica das sementes ocorreu entre 84 e 105 dias, a colheita deve ser feita entre 84 e 98 dias, e a deiscência dos frutos ocorre 105 dias após a antese. O teor de água e a massa de matéria seca foram os índices que melhor caracterizaram a maturação fisiológica e época de colheita das sementes; o tamanho dos frutos e a coloração das sementes revelaram-se como bons indicadores do ponto de maturação fisiológica. A maior porcentagem de germinação foi obtida entre 77 e 110 dias, e o vigor das sementes aumenta até 91 dias após a antese. As sementes de Tibouchina granulosa apresentaram dormência após a maturação fisiológica.
\end{abstract}

Termos para indexação: Tibouchina granulosa, germinação, vigor, época de coleta, matéria seca.

\section{Physiological maturity of quaresmeira seeds}

\begin{abstract}
The objective of this work was to study the maturation process of Tibouchina granulosa Cogn. seeds. Each inflorescence was identified in the day of its respective anthesis. Samples of fruits and seeds were collected weekly, and diameter, weight, color, moisture content and dry matter were determined. After seed extraction, analyzes were made for coloring, moisture content, dry matter, 1,000 seeds mass, speed and percentage of germination. Experimental design was carried out in a completely randomized block with four replications. Analysis of data obtained led to the following conclusions: seeds physiological maturity occurred 84 to 105 days, and seed harvest should be done between 84 to 98 days after the anthesis. The parameters which best characterized seed physiological maturity and the time for harvesting were moisture content and dry matter weight. The largest germination percentage was verified in extracted seeds from 77 until 105 days after the anthesis, and seeds vigor increased until 91 days. The size and color of fruits and seeds demonstrated efficiency as maturation parameters. Fruits initial dehiscences occurred after 105 days of the anthesis. Tibouchina granulosa presented seed dormancy after maturation.
\end{abstract}

Index terms: Tibouchina granulosa, germination, vigor, harvest period, dry matter.

\section{Introdução}

A quaresmeira (Tibouchina granulosa Cogn.), planta da família Melastomataceae, é uma espécie da Mata Atlântica que pode crescer até os $12 \mathrm{~m}$ de altura, e seu tronco pode atingir $40 \mathrm{~cm}$ de diâmetro. Apresenta flores com tonalidades que vão do rosa ao roxo, com grande potencial para ser utilizada como planta ornamental, principalmente em floração, por isso é recomendável em projetos paisagísticos, bem como na arborização de ruas estreitas e sob redes elétricas (Lorenzi, 1998).
A utilização de qualquer espécie florestal não tradicional, para plantios com finalidade produtiva ou ambiental, necessita de estudos para o desenvolvimento de tecnologia adequada de produção, iniciando-se pelo conhecimento da qualidade da semente (Leonhardt et al., 2001).

A fase de máxima qualidade das sementes coincide com o ponto de maturação fisiológica, que compreende as transformações morfológicas, fisiológicas e funcionais que sucedem no óvulo fertilizado. A maturação é atingida quando a semente apresenta máximo conteúdo 
de matéria seca e acentuada redução no teor de água, alterações visíveis no aspecto externo de frutos e sementes, que culmina com máxima capacidade germinativa e vigor das mesmas (Popinigis, 1985; Carvalho \& Nakagawa, 2000). Nesse ponto a semente deve ser colhida.

A época ideal para a colheita das sementes, em virtude da variação que pode ocorrer em função da espécie, da cultivar e das condições de ambiente, é identificada por meio do estudo e do estabelecimento de alguns parâmetros denominados índices de maturação (Edwards, 1980). Vários autores recomendam proceder à etiquetagem das flores na antese e à coleta periódica das sementes para acompanhamento desses parâmetros, que são modificações morfológicas e fisiológicas como teor de água, tamanho, forma, cor, conteúdo de matéria fresca, conteúdo de matéria seca, capacidade germinativa e vigor, até a fase em que a semente deixa de receber nutrientes da planta (Delouche, 1981; Popinigis, 1985; Mayer \& Poljakoff-Mayber, 1989; Carvalho \& Nakagawa, 2000). Entretanto, esses parâmetros, a serem utilizados na identificação do ponto de maturidade fisiológica, variam entre e dentro da espécie e de acordo com o habitat natural (Aguiar et al., 1993). Além de permitir estabelecer o ponto de maturidade fisiológica da semente, auxiliam na avaliação da extensão de sua deterioração em condições de campo (Barbedo et al., 1994).

Na região serrana do Caparaó, ES, muitas são as dificuldades de se promover a reprodução dessa espécie de forma assistida, pois ela apresenta frutos deiscentes e uma taxa muito baixa de germinação, dificultando a dispersão e o repovoamento na região.

O objetivo deste trabalho foi estudar a maturação fisiológica das sementes de Tibouchina granulosa, a fim de estabelecer o momento ideal para a coleta dos frutos.

\section{Material e Métodos}

Os trabalhos foram desenvolvidos na região serrana do Caparaó, em Ibitirama, ES, num fragmento de Mata Atlântica, no município de Guaçuí, ES, e no Departamento de Fitotecnia do Centro de Ciências Agrárias da Universidade Federal do Espírito Santo (CCA-Ufes), Alegre, ES, no período de janeiro de 2002 a dezembro de 2003.

Para o estudo da maturação fisiológica das sementes, as flores foram etiquetadas na antese floral, no dia 27 de março de 2003, e as coletas de frutos foram rea- lizadas a cada sete dias, iniciadas no dia 3 de abril e terminadas no dia 10 de julho de 2003.

A partir das flores marcadas na antese floral, frutos formados a cada semana foram coletados, conduzidos ao Laboratório de Sementes, onde foram avaliados, as sementes foram extraídas manualmente, e foram feitas as determinações dos parâmetros morfológicos e fisiológicos descritos a seguir.

Diâmetro, massa e coloração dos frutos foram determinados com auxílio de paquímetro e balança eletrônica; o teor de água dos frutos foi determinado pelo método de estufa a $105 \pm 3^{\circ} \mathrm{C}$, durante 24 horas, de acordo com as Regras para Análise de Sementes (Brasil, 1992); a massa da matéria seca dos frutos foi conduzida conjuntamente com o teor de água, e os resultados expressos em mg; a coloração das sementes foi determinada no momento em que eram extraídas dos frutos; o teor de água e a massa de matéria seca das sementes foram obtidos pelo método de estufa a $105 \pm 3^{\circ} \mathrm{C}$, durante 24 horas, conforme Brasil (1992), com duas subamostras de aproximadamente $0,1 \mathrm{~g}$, sendo o primeiro expresso em porcentagem e o segundo expresso em mg por $100 \mathrm{mg}$ de sementes; a massa de 1.000 sementes foi determinada de acordo com Brasil (1992), com oito repetições de 100 sementes, utilizando-se de balança eletrônica, e a média dos resultados expressa em mg.

O teste de germinação foi realizado com quatro subamostras de 50 sementes, colocadas sobre duas folhas de papel umedecidas, com 2,5 vezes a sua massa com solução de ácido giberélico $\left(\mathrm{GA}_{3}\right)$ à concentração de $0,05 \%$, em placas de Petri previamente esterilizadas. Os testes de germinação foram conduzidos em câmaras de germinação do tipo BOD, com temperatura alternada de $20^{\circ} \mathrm{C}-30^{\circ} \mathrm{C}$, e a germinação foi avaliada pela porcentagem de plântulas normais, no final do teste, conforme Brasil (1992). A velocidade de germinação foi determinada pelo índice de velocidade de germinação (IVG), obtido pela fórmula de Maguirre (1962), e as sementes germinadas, isto é, aquelas que apresentavam protrusão de raiz primária maior ou igual a $2 \mathrm{~mm}$ de comprimento, foram contadas diariamente durante a condução dos experimentos.

O delineamento experimental utilizado, em todas as avaliações, foi o inteiramente casualizado, com quatro repetições de 50 frutos e/ou sementes, à exceção da coloração e da massa de 1.000 sementes. Os dados obtidos foram analisados por regressão polinomial, tendose estabelecido como nível de significância $\mathrm{P}<0,05$ dos 
testes. As análises estatísticas foram efetuadas utilizando-se o Sistema de Análises Estatísticas e Genéticas SAEG.

\section{Resultados e Discussão}

A época de florescimento, que corresponde ao período decorrido do início à completa formação dos botões florais, teve início na primeira quinzena de fevereiro em Guaçuí, e na segunda quinzena de fevereiro, em Ibitirama; estendeu-se até início de outubro, concordando com Lorenzi (1998), que afirma que a floração dessa espécie ocorre duas vezes ao ano, de junho a agosto e de dezembro a março.

Na Tabela 1 são apresentadas as características físicas e morfológicas dos frutos e das sementes de Tibouchina granulosa, em cada uma das 15 épocas em que foram colhidas. O início da frutificação se deu entre 14 e 21 dias após a antese, fase de abertura das flores, e a deiscência dos frutos teve início aos 105 dias.

O diâmetro e o peso dos frutos apresentaram incrementos mais acentuados entre a primeira e a segunda colheita (7 e 14 dias após a antese), seguindo-se um pequeno e progressivo aumento até a décima colheita aos 70 dias. Com relação à coloração, verificou-se que os frutos da primeira colheita apresentaram uma coloração verde, com pequenas pontuações vermelho-brilhantes, que se mantiveram até cerca de 21 dias após a antese. Desse estádio até aos 70 dias, as tonalidades foram se alterando, tomando tons um pouco mais escuros, passando à coloração vermelho-marrom, que foi se tornando menos brilhante e mais escuro (marrom-escuro) até os 91 dias e, posteriormente, perdendo ainda mais o brilho, adquirindo tom mais acinzentado e adquirindo

Tabela 1. Parâmetros físicos e morfológicos dos frutos e sementes de Tibouchina granulosa, coletados durante 105 dias após a antese.

\begin{tabular}{cccll}
\hline $\begin{array}{c}\text { Dias após a } \\
\text { antese }\end{array}$ & $\begin{array}{c}\text { Diâmetro } \\
\text { dos frutos } \\
(\mathrm{mm})\end{array}$ & $\begin{array}{c}\text { Massa dos } \\
\text { frutos }(\mathrm{mg})\end{array}$ & Coloração dos frutos & $\begin{array}{c}\text { Coloração das } \\
\text { sementes }\end{array}$ \\
\hline 7 & 368 & 61 & Verde-vermelha & Branca \\
14 & 668 & 235 & Verde-vermelha & Branca \\
21 & 581 & 168 & Verde-vermelha & Branca \\
28 & 768 & 368 & Verde-vermelha-marrom & Branca-amarela \\
35 & 725 & 320 & Verde-vermelha-marrom & Amarela-marrom \\
42 & 825 & 342 & Vermelha-marrom & Amarela-marrom \\
49 & 781 & 368 & Vermelha-marrom & Amarela-marrom \\
56 & 831 & 421 & Vermelha-marrom & Marrom-claro \\
63 & 800 & 384 & Vermelha-marrom & Marrom-claro \\
70 & 825 & 406 & Vermelha-marrom & Marrom \\
77 & 825 & 448 & Marrom-escuro & Marrom \\
84 & 806 & 395 & Marrom-escuro & Marrom \\
91 & 837 & 448 & Marrom-escuro & Marrom-escuro \\
98 & 837 & 445 & Marrom-escuro e cinza & Marrom-escuro \\
105 & 831 & 446 & Marrom-escuro e cinza & Marrom-escuro \\
\hline
\end{tabular}

um formato do tipo pixídio. A partir desse ponto, verificou-se que, entre 98 e 105 dias, ocorria o início de deiscência através de uma abertura, por onde são liberadas as sementes.

As sementes apresentaram um contínuo processo de mudanças em sua coloração, passando de brancas nas primeiras semanas, para amarelas, marrons, até adquirir a coloração marrom-escuro, aos 91 dias após a antese, permanecendo com essa coloração até a última coleta. O número de sementes por fruto não apresentou alteração durante a fase de maturação, mantendose em média com cerca de $760 \pm 21$ sementes, por fruto, o que sugere que o número de sementes formadas no fruto esteja mais relacionado com a taxa de polinização e fertilização do que com a idade do fruto.

A utilização de características como coloração de frutos e sementes, para determinar o ponto de maturação fisiológica das sementes da espécie estudada, não é muito precisa, pois essas características são relativamente difíceis de serem determinadas, já que cada pessoa tem percepção diferente das mesmas cores. Porém, a correlação de um parâmetro visual de mudança de coloração dos frutos, com as épocas de maturação das sementes, associadas a outros índices, tem sido relatada por Corvello et al. (1999) para cedro (Cedrela fissilis Vell.). O peso e o diâmetro dos frutos não são parâmetros muito seguros para indicar a maturidade das sementes de Tibouchina granulosa, pois atingem valores próximos do máximo relativamente cedo, o que geralmente acontece com sementes florestais (Edwards, 1980), como observaram Leonhardt et al. (2001), ao trabalhar com sementes de Citharexylum montevidense.

As variáveis massa, diâmetro, teor de água dos frutos, massa de matéria seca dos frutos, teor de água e massa de matéria seca das sementes ajustaram-se ao modelo de regressão polinomial de ordem 2 (Figura 1). Os parâmetros germinação e vigor, avaliado pelo índice de velocidade de germinação, ajustaram-se ao mesmo modelo de regressão (Figura 1).

O teor de água dos frutos (Figura 2) apresentou decréscimos contínuos e progressivos, durante todas as épocas de colheita, que ficaram evidenciados principalmente a partir da quarta colheita, 28 dias após a antese. Aos 105 dias, após a antese, os frutos ainda apresentavam teor de água de 51,8\%; nesse ponto apresentavam coloração marrom-escuro e cinza, opaca, com o mesocarpo bastante verdolengo, e as sementes já ofereciam facilidade para serem removidas dos mesmos. Nas sementes, nas primeiras colheitas realizadas, quan- 
do os frutos se encontravam em fase de crescimento, após sete e 14 dias da antese, o teor de água foi de $85 \pm 1,1 \%$. A partir desse ponto, nas colheitas que se seguiram de 21 até 70 dias após a antese, o teor de água das sementes decresceu progressiva e paulatinamente, assumindo valores de 29,2\%. Após 85 dias da antese, até 105 dias, o teor de água se reduziu de forma menos expressiva, atingindo cerca de $23,2 \%$, conforme carac-
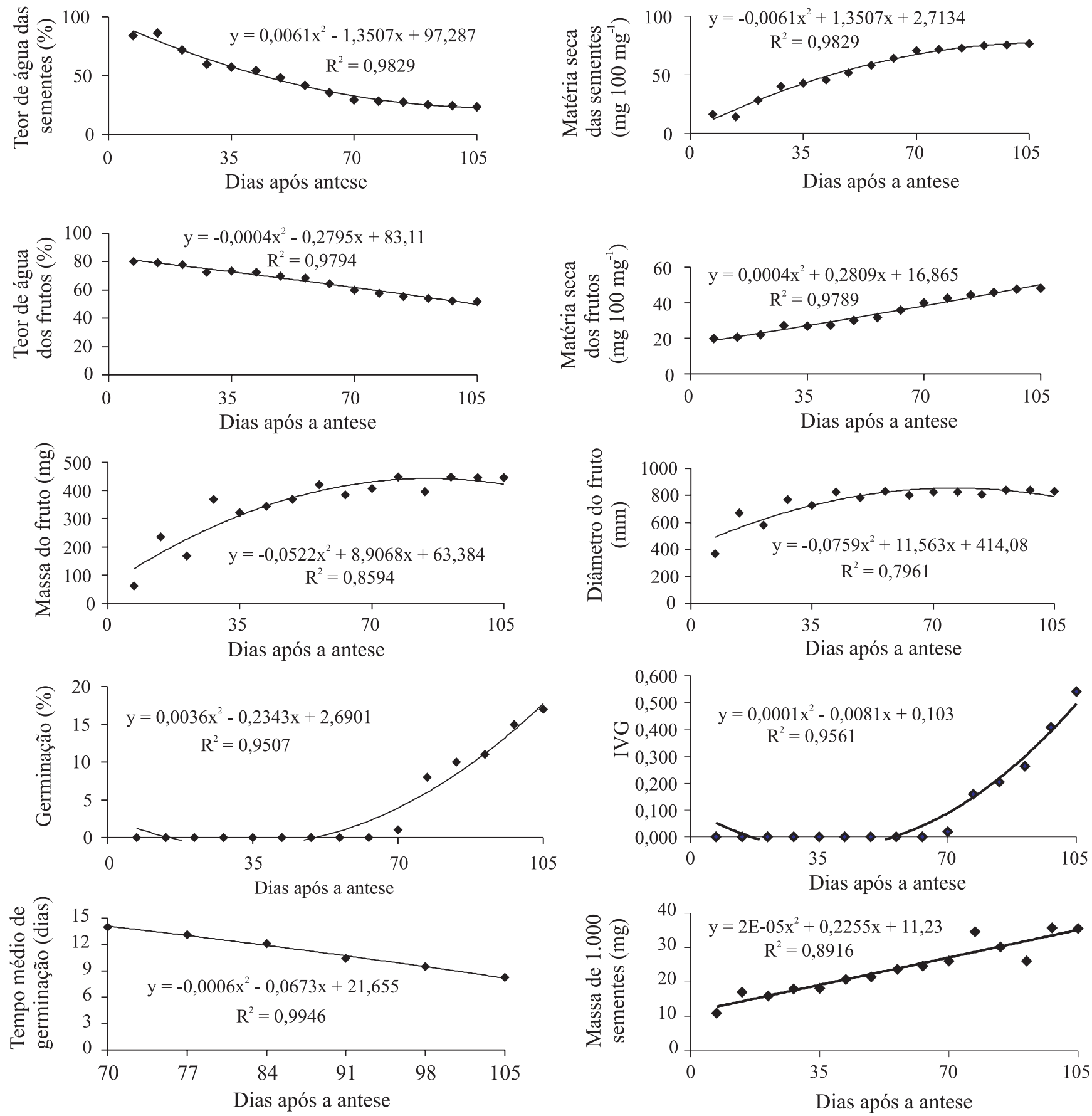

Figura 1. Teor de água e matéria seca das sementes; teor de água, matéria seca, massa e diâmetro dos frutos; germinação, índice de velocidade de germinação (IVG), tempo médio de germinação e massa de 1.000 sementes de Tibouchina granulosa, em razão de dias após a antese. 
terizada pela curva obtida a partir da equação de regressão (Figura 1).

A massa de matéria seca teve comportamento inversamente proporcional à umidade (Figura 2), com correlação altamente negativa (Tabela 2), tendo apresentado valores de 16,1 mg por 100 sementes, aos sete dias após a antese. Aos 77 dias após a antese, quando os frutos ainda apresentavam coloração marrom, foram atingidos valores de 71,8 mg por 100 sementes, que se mantiveram inalterados até a penúltima coleta, tendo aumentado para 76,8 mg por 100 sementes na última coleta (105 dias após a antese), com frutos de coloração marrom-escuro. Pela curva ajustada a partir da equação de regressão polinomial (Figura 1), aos 84 dias a MS atingiu valor máximo.

Verificou-se uma correlação positiva (Tabela 2) da massa de matéria seca com a massa de 1.000 sementes. Os valores cresceram, significativamente, até a 11a coleta (77 dias). A curva obtida a partir da equação de regressão (Figura 1) mostra que o aumento da mas-

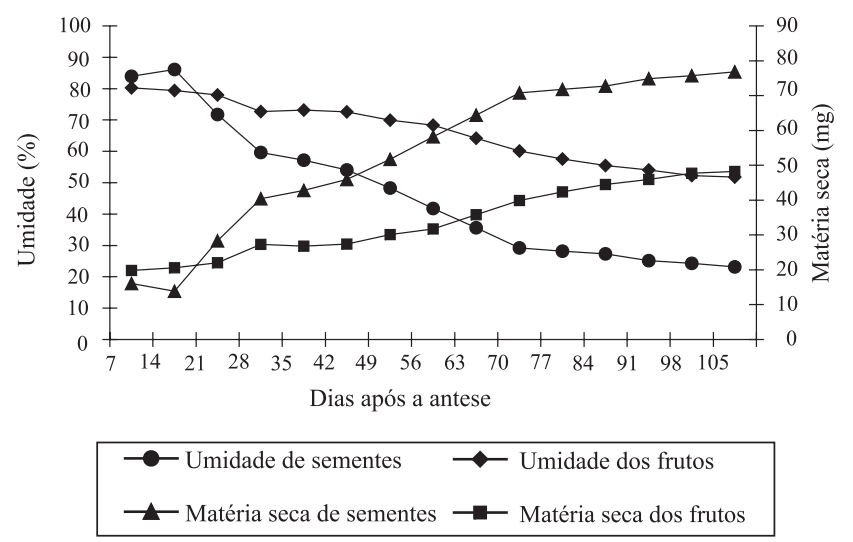

Figura 2. Teor de água e matéria seca de sementes e frutos de Tibouchina granulosa, em razão de dias após a antese. sa de 1.000 sementes também foi crescente e maior até a 11a coleta, concordando com a massa de matéria seca das sementes. Essa similaridade de comportamento resultou na correlação positiva obtida entre eles, e negativa em relação ao teor de água (Tabela 2).

Carvalho \& Nakagawa (2000) fazem uma relação entre o ponto em que a umidade começa a decrescer rapidamente com a proximidade dos parâmetros de maturação, germinação, vigor e massa de matéria seca, e Popinigis (1985) correlaciona o ponto de maturação fisiológica com a máxima massa de matéria seca acumulada pelas sementes. É o ponto, após o qual, a semente nada recebe, ou quase nada, da planta onde ela se formou (Carvalho \& Nakagawa, 2000). Guimarães et al. (1998) ao trabalhar com Zinnia elegans Jacq. constataram que esse parâmetro não pode ser utilizado de maneira eficaz como índice de maturidade. Similaridade de resultados foi obtida por Leonhardt et al. (2001) em sementes de Citharexylum montevidense.

$\mathrm{Na}$ avaliação da capacidade germinativa das sementes, nas nove primeiras coletas não se obteve germinação, fato que possivelmente pode estar associado à imaturidade fisiológica da semente. O início de germinação (protrusão da raiz primária da primeira semente), somente se verificou após 70 dias (Figura 1), sem, contudo, originar uma plântula normal, de acordo com Brasil (1992). A partir dessa coleta, os valores de porcentagem de germinação aumentaram, atingindo maiores valores em sementes extraídas de frutos com 77, 84, 91, 98 e 105 dias após a antese floral, com 8\%, 10\%, 11\%, $15 \%$ e $17 \%$, respectivamente.

De maneira análoga, o vigor avaliado pelo índice de velocidade de germinação apresentou valores crescentes (Figura 1), até 91 dias, tendo-se mantido nos níveis mais altos e similares nas últimas três coletas, 91, 98 e 105 dias, com correlação altamente positiva $(r=0,98)$

Tabela 2. Coeficientes de correlação simples (r) entre diâmetro (DF), massa (M), teor de água (TAF) e matéria seca dos frutos (MSF); teor de água (TAS) e matéria seca (MSS) de sementes; massa de 1.000 sementes (MMS); germinação (GERM); índice de velocidade de germinação (IVG); e tempo médio de germinação (TMG), obtidos no estudo da maturação de sementes de Tibouchina granulosa.

\begin{tabular}{|c|c|c|c|c|c|c|c|c|c|}
\hline Parâmetros & M & TAF & MSF & TAS & MSS & MMS & GERM & IVG & TMG \\
\hline $\mathrm{DF}$ & $0,96^{* *}$ & $-0,71 * *$ & $0,71^{* *}$ & $-0,80^{* *}$ & $0,80 * *$ & $0,74 * *$ & 0,41 & 0,38 & $-0,52$ \\
\hline M & - & $-0,82 * *$ & $0,82^{* *}$ & $-0,89 * *$ & $0,89 * *$ & $0,83 * *$ & $0,54 *$ & 0,51 & $-0,56$ \\
\hline TAF & - & - & $-1,00 * *$ & $0,96^{* *}$ & $-0,96 * *$ & $-0,94 * *$ & $-0,86 * *$ & $-0,81 * *$ & $0,97^{* *}$ \\
\hline MSF & - & - & - & $-0,96^{* *}$ & $0,96 * *$ & $0,94 * *$ & $0,86^{* *}$ & $0,81^{* *}$ & $0,97 * *$ \\
\hline TAS & - & - & - & - & $-1,00^{*}$ & $-0,90 * *$ & $-0,69 * *$ & $-0,65^{* *}$ & $0,99^{* *}$ \\
\hline MSS & - & - & - & - & - & $0,90^{* *}$ & $0,69 * *$ & $0,65^{* *}$ & $-0,99$ \\
\hline MMS & - & - & - & - & - & - & $0,83 * *$ & $0,79 * *$ & $-0,50$ \\
\hline GERM & - & - & - & - & - & - & - & $0,98^{* *}$ & $-0,94 * *$ \\
\hline IVG & - & - & - & - & - & - & - & - & $-0,98^{* *}$ \\
\hline
\end{tabular}

* e **Significativo a 5\% e a $1 \%$ pelo teste t, de acordo com Cruz \& Regazzi (1994). 
com a porcentagem de germinação das sementes. O índice de velocidade de germinação passou de 0,018 , na décima semana de coleta, para 0,541 na décima quinta semana. O momento em que as sementes começaram a germinar determinou o instante real do início da maturação, que começou aos 77 dias após a antese floral, tendo-se mantido inalterado até os 105 dias. A maturação só muda de estádio entre 91 e 105 dias após a antese, quando o vigor aumenta, significativamente, em relação às demais coletas e se mantém estável. Nessa fase, como observado anteriormente, o diâmetro, a massa e a matéria seca dos frutos e sementes mantiveram-se em níveis praticamente constantes, o que confirma a maturação fisiológica das sementes da espécie, quando os frutos apresentam coloração marromescuro e cinza. Entretanto, nas análises feitas, verificou-se que as sementes de Tibouchina granulosa apresentam dormência após a maturação fisiológica, com baixa porcentagem de germinação.

\section{Conclusões}

1. A coleta das sementes de Tibouchina granulosa, na maturação fisiológica, na região serrana do Caparaó, deve ser feita entre 84 e 105 dias após a antese, com teor de água entre $25 \%$ e $27 \%$ e coloração marromescuro.

2. A deiscência dos frutos ocorre após 105 dias da antese.

3. O tamanho dos frutos e a coloração das sementes são bons indicadores do ponto de maturação fisiológica.

4. As sementes de Tibouchina granulosa apresentam dormência após a maturação fisiológica, com baixa porcentagem de germinação.

\section{Agradecimentos}

Ao CNPq pela concessão de bolsas; aos proprietários da Fazenda Tecnotruta, pelo apoio e auxílios prestados na preservação, acesso e coleta de sementes na região do Parque Nacional do Caparaó; aos funcionári- os Nilton Capucho e Jânio Rezende, pelo apoio nas coletas de sementes; a Marilda Torres Capucho e José Maria Barbosa pelo auxílio no laboratório.

\section{Referências}

AGUIAR, I.B.; PIÑA-RODRIGUES, F.C.M.; FIGLIOLIA, M.B. Sementes florestais tropicais. Brasília: ABRATES, 1993. 350p.

BARBEDO, A.S.C.; ZANIN, A.C.W.; BARBEDO, C.J.; NAKAGAWA, J. Efeitos da idade e do período de repouso póscolheita dos frutos sobre a qualidade de sementes de berinjela. Horticultura Brasileira, v.12, p.14-18, 1994.

BRASIL. Ministério da Agricultura e Reforma Agrária. Regras para análise de sementes. Brasília: SNDA/DNDV/CLAV, 1992. 365p.

CARVALHO, N.M.; NAKAGAWA, J. Sementes: ciência, tecnologia e produção. 4.ed. Jaboticabal: Funep, 2000. 588p.

CORVELLO, W.B.V.; VILLELA, S.A.; NEDEL, J.L.; PESKE, S.T. Maturação fisiológica de sementes de cedro (Cedrela fissilis Vell.). Revista Brasileira de Sementes, v.21, p.23-27, 1999.

DELOUCHE, J.C. Seed maturation. In: Handbook of seed technology. Mississipi: Mississipi State University, 1981. p.17-23.

EDWARDS, D.G.W. Maturity and quality of tree seeds. Seed Science and Technology, v.8, p.625-657, 1980.

GUIMARÃES, T.G.; OLIVEIRA, D.A.; MANTOVANIALVARENGA, E.; GROSSI, J.A.S. Maturação fisiológica de sementes de zínia (Zinnia elegans Jacq.). Revista Brasileira de Sementes, v.20, p.7-11, 1998.

LEONHARDT, C.; TILLMANN, M.A.A.; VILLELA, F.A.; MATTEI, V.L. Maturação fisiológica de sementes de tarumã-deespinho (Citharexylum montevidense (Spreng.) Moldenke Verbenaceae), no Jardim Botânico de Porto Alegre, RS. Revista Brasileira de Sementes, v.23, p.100-107, 2001.

LORENZI, H. Árvores brasileiras: manual de identificação e cultivo de plantas arbóreas nativas do Brasil. Nova Odessa: Plantarum, 1998. v.1. 352p.

MAGUIRRE, J.B. Speed of germination-aid in selection and evaluation for seedling emergence vigor. Crop Science, v.2, p.176177, 1962

MAYER, A.M.; POLJAKOFF-MAYBER, A. The germination of seeds. London: Pergamon Press, 1989. 270p.

POPINIGIS, F. Fisiologia da semente. Brasília: Agiplan, 1985. 289p. 